Article

\title{
Aryliodonium Ylides as Novel and Efficient Additives for Radical Chemistry: Example in Camphorquinone (CQ)/Amine Based Photoinitiating Systems
}

\author{
Julie Kirschner ${ }^{1}$, Julien Paillard ${ }^{1}$, Mariem Bouzrati-Zerelli ${ }^{1}$, Jean-Michel Becht ${ }^{1}$, \\ Joachim E. Klee ${ }^{2}$, Saloua Chelli ${ }^{3}$, Sami Lakhdar ${ }^{3}$ (D) and Jacques Lalevée ${ }^{1, *}$ \\ 1 Institut de Science des Matériaux de Mulhouse IS2M, UMR CNRS 7361, UHA, 15 rue Jean Starcky, \\ 68057 Mulhouse CEDEX, France \\ 2 Dentsply Sirona, De-Trey-Straße 1, 78462 Konstanz, Germany \\ 3 Normandie Univ., LCMT, ENSICAEN, UNICAEN, CNRS, 6, Boulevard Maréchal Juin, 14000 Caen, France \\ * Correspondence: jacques.lalevee@uha.fr; Tel./Fax: +33-3-89-60-88-03
}

Academic Editor: John C. Walton

Received: 22 July 2019; Accepted: 9 August 2019; Published: 11 August 2019

\begin{abstract}
Diaryliodonium salts are well-established compounds in free radical chemistry and are already used as photoinitiators (free radical or cationic polymerization), but the presence of counter anions is a strong drawback. Indeed, a counter anion is always required (e.g., $\mathrm{SbF}_{6}{ }^{-}$) leading to potential toxicity issues or release of HF. In the present paper, counter anion-free and fluoride-free aryliodonium salts are proposed, that is, aryliodonium ylides (AY) are studied here as new and efficient additives for radical chemistry and an example is provided for the camphorquinone (CQ)/amine based photoinitiating systems (PISs) for the polymerization of thick (1.4 $\mathrm{mm}$ ) and thin $(20-13 \mu \mathrm{m})$ methacrylates under air and blue light irradiation. The newly proposed PISs, for example, $\mathrm{CQ} /$ amine/AY, presented excellent polymerization performances and good bleaching properties were obtained after polymerization. Real-time Fourier transform infrared spectroscopy (RT-FTIR) was used to monitor the photopolymerization profiles. The chemical mechanisms involved were investigated using electron spin resonance (ESR).
\end{abstract}

Keywords: photoinitiator; iodonium salt; radical initiation; photopolymerization

\section{Introduction}

Photoinitiated polymerization has been widely used in the past decades and has found many industrial applications, such as 3D printing, coatings, inks, adhesives, and so on. Two types of polymerization can be distinguished depending on the nature of the photoinitiator used; free radical photopolymerization and cationic polymerization [1,2]. The latter presents numerous advantages compared to the former, such as insensitivity to oxygen, low shrinkage during curing, dark polymerization after the removal of the light source, and so on [3] Two families of cationic photoinitiators are generally used: iodonium and sulfonium salts $[1,4,5]$. As iodonium salts present better solubility in non-polar monomers than the corresponding sulfonium salts, they are the most widespread cationic photoinitiators [6]. Iodonium salts are also usually very efficient, but absorb at shorter wavelengths. Diphenyliodonium salts associated with $\mathrm{BF}_{4}{ }^{-}, \mathrm{PF}_{6}{ }^{-}, \mathrm{AsF}_{6}{ }^{-}, \mathrm{SbF}_{6}{ }^{-}$as counter anions are the simplest and the most frequently used $[1,6]$. The cationic part of the diphenyliodonium salt is responsible for light absorption whereas the nature of the counter anion governs the strength of the acid formed during photolysis [1]. Nevertheless, the diaryliodonium photoinitiators used currently all exhibit absorption properties in the UV absorption range between 220 and $280 \mathrm{~nm}$ while there are no light sources efficient enough operating in this spectral range $[1,6-9]$. To overcome their 
poor absorption properties in the visible range, diaryliodonium salts can be used in combination with a photosensitizer (PS) and/or a visible free radical photoinitiator [10]. As proposed by Crivello, diaryliodonium salts can be sensitized by the PS through an electron or energy transfer process [11]. After excitation of the PS and reduction of the diaryliodonium salt, aryl radicals are generated through the cleavage of the C-I bond [11-15].

On the other hand, two types of photoinitiator (PI) are used in free radical photopolymerization: Type I and Type II PI [1]. Due to its good visible absorption properties, camphorquinone is the most common Type II PI used for the free radical photopolymerization of (meth-)acrylates under blue light irradiation. To be efficient, camphorquinone has to be used in combination with a hydrogen donor, for example, an amine [16-18]. The performances of the camphorquinone (CQ)/amine system can also be improved in the presence of well-chosen additives, such as diaryliodonium salts, as they generate initiating aryl radicals upon light irradiation [1]. Diaryliodonium hexafluorophosphates (e.g., diphenyliodonium hexafluorophosphate, Speedcure 938, and so on) are frequently used diaryliodonium salts, due to their commercial availability $[19,20]$. Nevertheless, in certain conditions, the hexafluorophosphate counter anion may cause some issues due to the release of HF [21,22].

The idea of this paper is to develop new counter anion-free and fluoride-free aryliodonium salts to avoid the formation of side products, for example, formation of HF and to enhance their solubility in monomers. In this paper, we describe two aryliodonium ylides (S5 and S6) as new efficient aryliodonium salts and additives for $\mathrm{CQ} / \mathrm{amine}$ based systems for the free radical polymerization of methacrylates under visible light irradiation. Aryliodonium ylides (AY) were studied for the replacement of traditionally used diaryliodonium salts (diphenyliodonium salt, Speedcure 938, and so on) in the $\mathrm{CQ} / \mathrm{amine}$ system. The performances of the newly proposed $\mathrm{CQ} / \mathrm{amine} / \mathrm{AY}$ systems for the free radical photopolymerization of thick and thin samples of methacrylates were evaluated using real-time FTIR experiments. Electron spin resonance (ESR) spectroscopy was used to identify the radicals generated upon light irradiation. A chemical mechanism between CQ and aryliodonium ylide is proposed.

\section{Materials and Methods}

\subsection{Materials}

S5 and S6 (Scheme 1) were prepared according to a synthetic procedure already described in the literature [23]. Camphorquinone was obtained from Sigma Aldrich (St. Louis, MO, USA) and used as a representative Type II PI (Scheme 2). Ethyl-4-(dimethylamino)benzoate (EDB) and 4-(dimethylamino)benzonitrile (DMABN) were used as additives in multicomponent systems and obtained from Sigma Aldrich or TCI Chemicals (Scheme 2). Speedcure938 (SC938) was obtained from Lambson Ltd. (Wetherby, UK, Scheme 2). Phenyl-N-tert-butylnitrone (PBN, Scheme 2) was used as spin trapping agent in the ESR experiments.
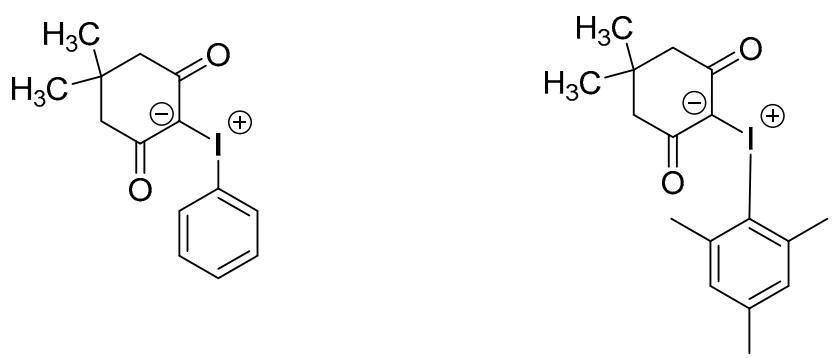

S5

S6

Scheme 1. Structures of the aryliodonium ylides (AY) studied: S5 and S6. 
<smiles>CCOC(=O)c1ccc(N(C)C(=O)CCCCCCC(C)(C)C)cc1</smiles><smiles>CC(C)(C)c1ccc([Hg](=O)c2ccc(C(C)(C)C)cc2)cc1</smiles><smiles>CCCCCCCC(C)(C)C</smiles>

Scheme 2. Structures of the photoinitiator (camphorquinone; CQ) and additives/co-initiators used.

Spectrum ${ }^{\circledR} \mathrm{TPH}^{\circledR} 3$ resin was received from Dentsply Sirona (Konstanz, Germany) and used as a representative matrix of dental materials, consisting of a mixture of modified BisGMA, TEGDMA (Scheme 3) and other methacrylate monomers. PrimeBond Active ${ }^{\circledR}$ was received without photoinitiator from Dentsply Sirona and used as a representative formulation for the preparation of dental adhesives.

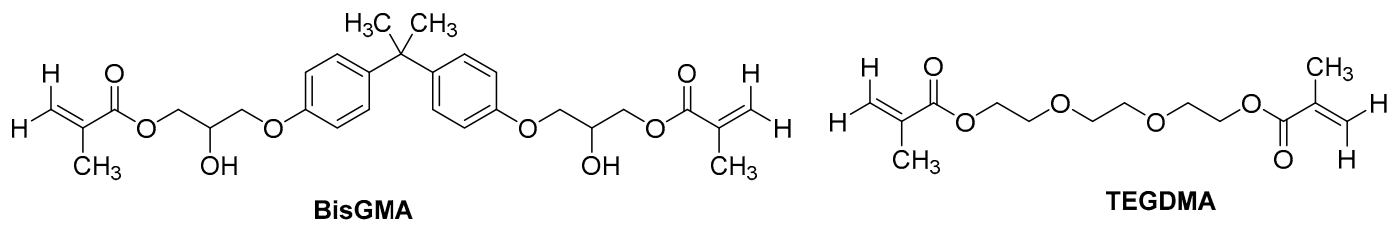

Scheme 3. Structures of the monomers used.

\subsection{Synthesis of Aryliodonium Ylides S5 and S6}

Synthesis of S5: iodobenzene diacetate $(0.20 \mathrm{~g}, 0.62 \mathrm{mmol}, 1$ equiv) was dissolved in ethanol $96 \%(1 \mathrm{M}, 0.62 \mathrm{~mL})$ under heating and added quickly to a dimedone $(0.087 \mathrm{~g}, 0.62 \mathrm{mmol}, 1$ equiv $)$ dissolved in a saturated aqueous solution of sodium carbonate $(0.3 \mathrm{M}, 1.90 \mathrm{~mL})$. The resulting mixture was stirred for $30 \mathrm{~min}$ at RT. Cold water $(2 \mathrm{~mL})$ was then added and the aqueous phase was extracted 3 times with $\mathrm{DCM}(3 \times 10 \mathrm{~mL})$. The organic phase was dried with anhydrous $\mathrm{MgSO}_{4}$ and concentrated under reduced pressure to give S5 $(0.12 \mathrm{~g}, 0.35 \mathrm{mmol}, 57 \%$ isolated yield $)$ as a white solid. ${ }^{1} \mathrm{H}$ NMR $\left(\mathrm{CDCl}_{3}, 300 \mathrm{MHz}\right) \delta(\mathrm{ppm}): 7.77(\mathrm{~d}, J=6 \mathrm{~Hz}, 2 \mathrm{H}), 7.47(\mathrm{~m}, 1 \mathrm{H}), 7.31(\mathrm{~m}, 2 \mathrm{H}), 2.45(\mathrm{~s}, 4 \mathrm{H}), 1.02(\mathrm{~s}, 6 \mathrm{H})$; ${ }^{13} \mathrm{C} \mathrm{NMR}\left(\mathrm{CDCl}_{3}, 50 \mathrm{MHz}\right) \delta$ (ppm): 188.4, 133.9, 131.5, 112.0, 94.6, 50.8, 32.1, 28.2; HRMS (ESI MS) $\mathrm{m} / \mathrm{z}$ : calculated: 343.0190 found: $343.0188\left((\mathrm{M}+\mathrm{H})^{+}\right.$detected $)$.

Synthesis of S6: dimedone $(0.19 \mathrm{~g}, 1.37 \mathrm{mmol}, 1$ equiv) was dissolved in a saturated solution of sodium carbonate $(0.3 \mathrm{M}, 1.70 \mathrm{~mL})$. Iodomesitylene diacetate $(0.50 \mathrm{~g}, 1.37 \mathrm{mmol}, 1$ equiv $)$ was dissolved in ethanol $96 \%(1 \mathrm{M}, 1.37 \mathrm{~mL})$ under heating. The solution of iodomesitylene was quickly added to the solution containing the conjugated base of dimedone. The resulting mixture was stirred for $30 \mathrm{~min}$ at RT. Cold water $(2 \mathrm{~mL})$ was then added and the aqueous phase was extracted 3 times with DCM $(3 \times 10 \mathrm{~mL})$. The organic phase was dried with anhydrous $\mathrm{MgSO}_{4}$ and concentrated in vacuo to give S6 $\left(0.34 \mathrm{~g}, 0.88 \mathrm{mmol}, 64 \%\right.$ isolated yield) as a light yellow powder. ${ }^{1} \mathrm{H} \mathrm{NMR}\left(\mathrm{CDCl}_{3}, 300 \mathrm{MHz}\right) \delta$ (ppm): $6.96(\mathrm{~s}, 2 \mathrm{H}), 2.72(\mathrm{~s}, 6 \mathrm{H}), 2.42(\mathrm{~s}, 4 \mathrm{H}), 2.28(\mathrm{~s}, 3 \mathrm{H}), 1.02(\mathrm{~s}, 6 \mathrm{H}) ;{ }^{13} \mathrm{C} \mathrm{NMR}\left(\mathrm{CDCl}_{3}, 50 \mathrm{MHz}\right) \delta$ (ppm): 187.9, 142.6, 129.5, 93.4, 50.9, 32.0, 28.1, 27.3; HRMS (ESI MS) $m / z$ : calculated: 385.0659 found: $385.0660\left((\mathrm{M}+\mathrm{H})^{+}\right.$detected $)$.

\subsection{Irradiation Sources}

A blue LED@477nm representative of dental materials usage (SmartLite Focus from Dentsply Sirona $\sim 300 \mathrm{~mW} \cdot \mathrm{cm}^{-2}$ in the selected conditions; see emission spectrum in Figure 1) and an LED centered at $455 \mathrm{~nm}$ (M455L3-ThorLabs; $\sim 80 \mathrm{~mW} \cdot \mathrm{cm}^{-2}$ ) were used for the irradiation of the photocurable samples. 


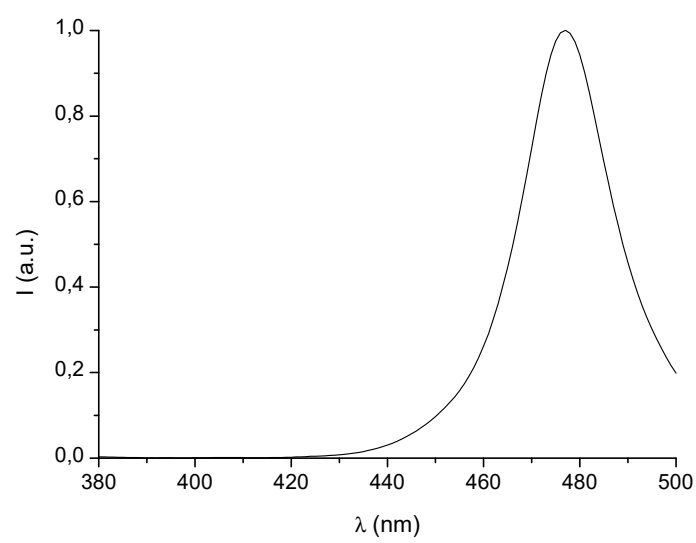

Figure 1. The emission spectrum of a blue LED centered at $477 \mathrm{~nm}$ (SmartLite Focus from Dentsply Sirona Germany).

\subsection{Absorption Experiments}

The UV-visible spectra were recorded using a JASCO V-730 UV/vis spectrophotometer (JASCO, Japan).

\subsection{Photopolymerization Experiments}

The photosensitive formulations were deposited on a polypropylene film and the sample thickness was controlled using a mold (1.4 mm thick samples). The samples were polymerized under air and irradiation with the LED source. The evolution of the methacrylate functions was continuously followed by real time FTIR spectroscopy (JASCO FTIR 6600, JASCO, Japan) at about $6165 \mathrm{~cm}^{-1}$ for thick $(1.4 \mathrm{~mm})$ methacrylate samples and at $1220 \mathrm{~cm}^{-1}$ for thin $(13-20 \mu \mathrm{m})$ ones.

\subsection{ESR Spin Trapping Experiments:}

ESR experiments were carried out using a Bruker EMX-plus spectrometer (X-band, Bruker Company, Rheinstetten, Germany). The radicals were generated at room temperature upon the blue LED exposure (SmartLite Focus from Dentsply Sirona) under $\mathrm{N}_{2}$. The radicals were trapped by phenyl-N-tert-butylnitrone (PBN, Scheme 2) according to a procedure already described [24]. The ESR spectra simulations were carried out using WINSIM software.

\section{Results and Discussion}

\subsection{Photochemical Mechanism}

In the presence of a spin trap agent $(\mathrm{PBN})$ for the photolysis of $\mathrm{CQ} / \mathrm{S} 5$ under $\mathrm{N}_{2}$ upon exposure to the blue LED centered at $477 \mathrm{~nm}$, the $\mathrm{Ph} \bullet / \mathrm{PBN}$ radical adducts were clearly observed (i.e., characterized by hyperfine coupling constants (hcfs) $\mathrm{a}_{\mathrm{N}}=14.0 \mathrm{G}, \mathrm{a}_{\mathrm{H}}=2.1 \mathrm{G}$ in agreement with hfcs known in the literature [25] (Figure 2)). Therefore, ESR spin trapping experiments showed the formation of phenyl radicals generated from the CQ/S5 interaction upon blue light. This result clearly highlights the cleavage of the C-I central bond of S5 and the possible release of benzene by the decomposition of S5 (through hydrogen abstraction process with the generated phenyl radical in S5). As benzene release must be clearly avoided in industrial applications for safety reasons, a derivative of S5 was prepared where the phenyl group was replaced by a 2,4,6-trimethylphenyl (mesityl) group: S6. 

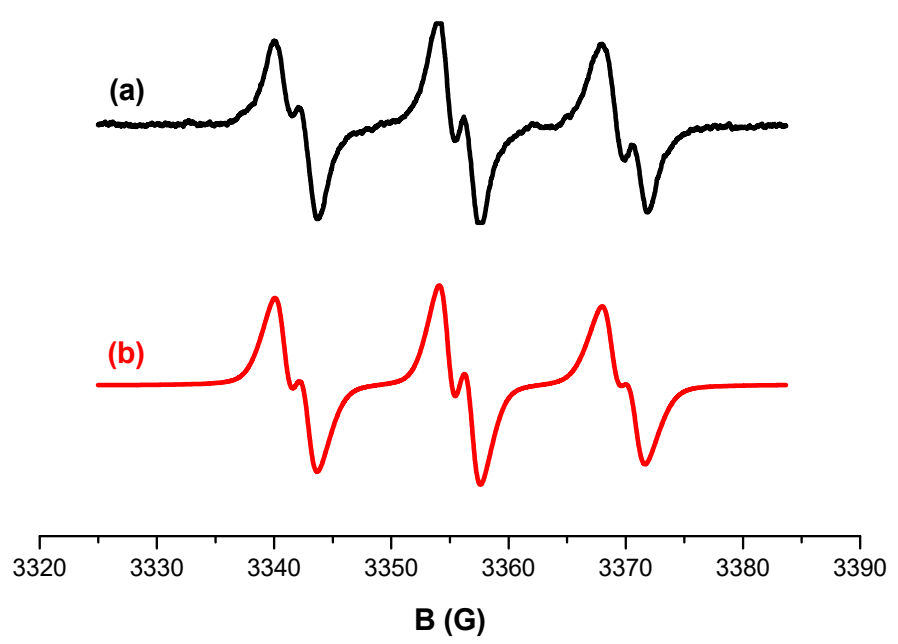

Figure 2. Electron spin resonance (ESR) spectra of the radicals generated in CQ/S5 (0.05 M/0.01 M) and trapped by phenyl-N-tert-butylnitrone (PBN) $(0.01 \mathrm{M})$ in tert-butylbenzene upon exposure to a LED@477 nm (SmartLite Focus): $\mathrm{N}_{2}$ saturated medium $\mathrm{Ph} / \mathrm{PBN}$ hyperfine coupling constants: $\mathrm{a}_{\mathrm{N}}=$ 13.96 G, $\mathrm{a}_{\mathrm{H}}=2.06 \mathrm{G}$; (a) experimental and (b) simulated spectra.

A general chemical mechanism for aryliodonium ylides can be proposed in agreement with the result obtained for the ESR spin trapping experiment for CQ/S5. Aryl radicals were generated according to reaction $1(\mathrm{r} 1)$ through an electron transfer between camphorquinone and the aryliodonium ylide (Ar-I-R).

$$
{ }^{*} \mathrm{CQ}+\mathrm{Ar}-\mathrm{I}-\mathrm{R} \rightarrow \mathrm{CQ}^{\bullet-}+\mathrm{Ar}^{\bullet}+\mathrm{R}=\mathrm{I}^{+}
$$

Aryl radicals could initiate the free radical polymerization of (meth)acrylate monomers in agreement with the good initiating ability of CQ/EDB/S5 vs. CQ/EDB found in polymerization experiments (see below, Figures 3 and 4).

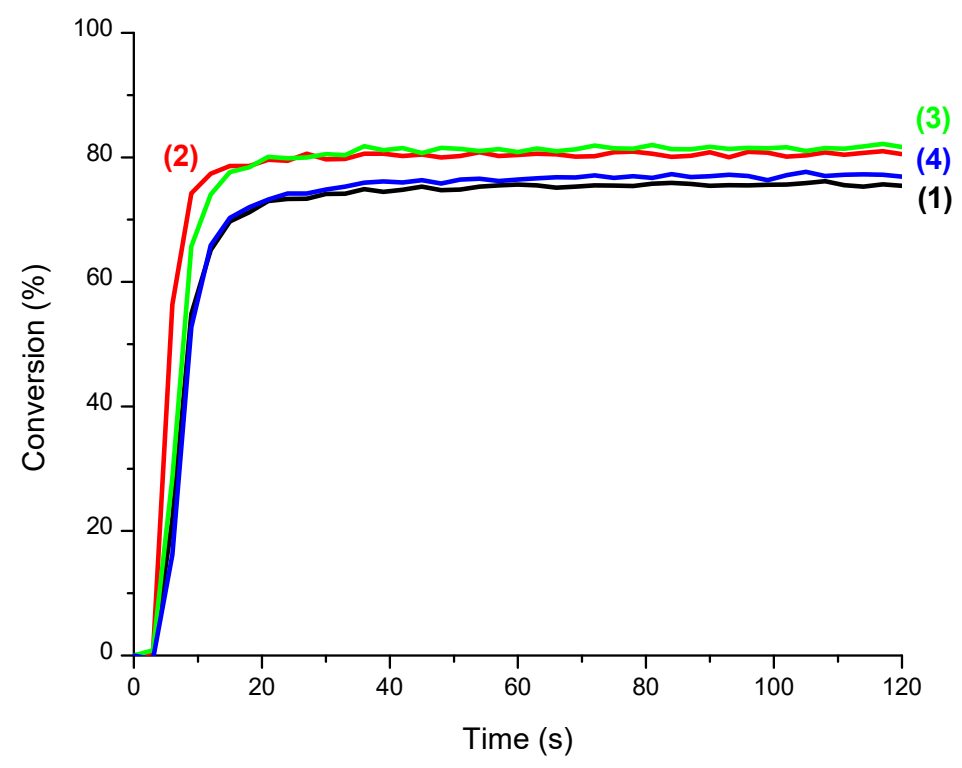

Figure 3. Photopolymerization profiles (methacrylate function conversion vs. irradiation time) for Spectrum ${ }^{\circledR} \mathrm{TPH}^{\circledR} 3$ resin (under air; $1.4 \mathrm{~mm}$ thick films) upon exposure to the LED@477 $\mathrm{nm}\left(\mathrm{I}_{0}=\right.$ $300 \mathrm{~mW} \cdot \mathrm{cm}^{-2}$ ) using different photoinitiating systems. (1) CQ/ethyl-4-(dimethylamino)benzoate (EDB) $(0.2 / 0.5 \% w / w) ;(2) \mathrm{CQ} / \mathrm{EDB} / \mathrm{SC} 938(0.2 / 0.5 / 1 \% w / w) ;(3) \mathrm{CQ} / \mathrm{EDB} / \mathrm{S} 5(0.2 / 0.5 / 1 \% w / w) ;(4) \mathrm{CQ} / \mathrm{EDB} / \mathrm{S} 6$ $(0.2 / 0.5 / 1 \% w / w)$. The irradiation starts for $\mathrm{t}=5 \mathrm{~s}$. 


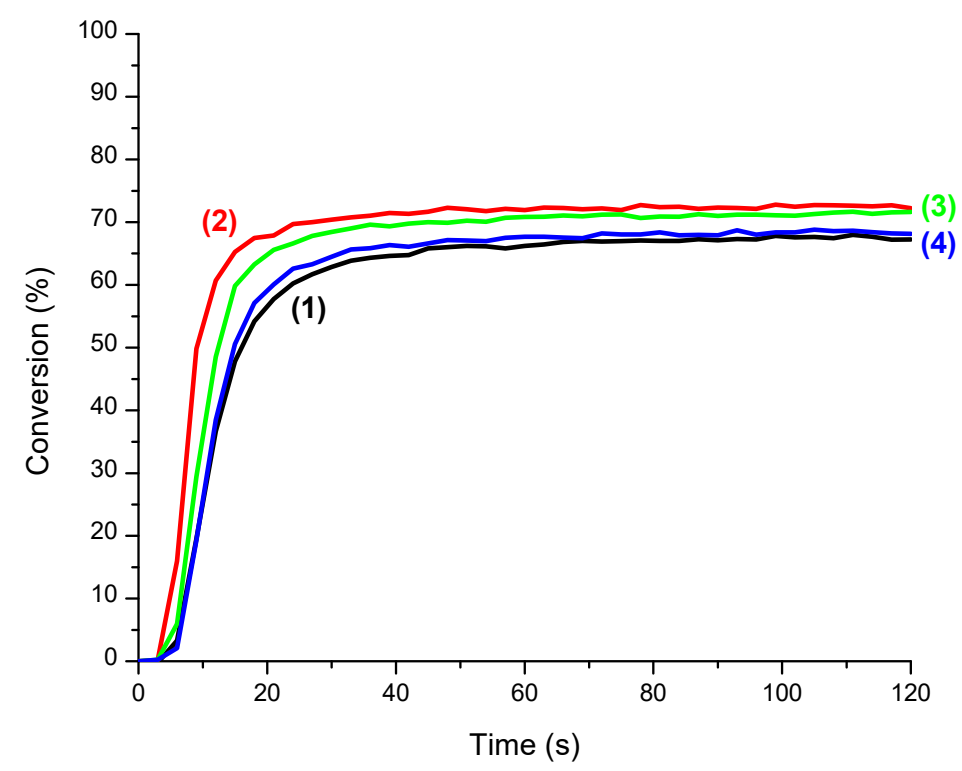

Figure 4. Photopolymerization profiles (methacrylate function conversion vs. irradiation time) for a Spectrum ${ }^{\circledR} \mathrm{TPH}^{\circledR} 3$ resin blend (under air; $1.4 \mathrm{~mm}$ thick films) upon exposure to the LED@455 $\mathrm{nm}\left(\mathrm{I}_{0}=\right.$ $\left.80 \mathrm{~mW} \cdot \mathrm{cm}^{-2}\right)$ using different photoinitiating systems. (1) CQ/EDB $(0.2 / 0.5 \% w / w) ;(2)$ CQ/EDB/SC938 $(0.2 / 0.5 / 1 \% w / w) ;(3) \mathrm{CQ} / \mathrm{EDB} / \mathrm{S} 5(0.2 / 0.5 / 1 \% w / w) ;(4) \mathrm{CQ} / \mathrm{EDB} / \mathrm{S} 6(0.2 / 0.5 / 1 \% w / w)$. The irradiation starts for $\mathrm{t}=5 \mathrm{~s}$.

In the presence of amine (EDB, DMABN), additional reactions were expected [1] r2-r4 leading to additional initiating radicals.

$$
\begin{gathered}
{ }^{*} \mathrm{CQ}+\mathrm{Me}_{2} \mathrm{NAr} \rightarrow \mathrm{CQ}-\mathrm{H}^{\bullet}+\mathrm{Me}\left(\mathrm{CH}_{2}{ }^{\bullet}\right) \mathrm{NAr} \\
\mathrm{CQ}-\mathrm{H}^{\bullet}+\mathrm{Ar}-\mathrm{I}-\mathrm{R} \rightarrow \rightarrow \mathrm{CQ}-\mathrm{H}^{-}+\mathrm{Ar} \\
\mathrm{CQ}-\mathrm{H}^{\bullet}+\mathrm{Ar}-\mathrm{I}-\mathrm{R} \rightarrow \rightarrow \mathrm{CQ}+\mathrm{H}^{+}+\mathrm{Ar}^{\bullet}
\end{gathered}
$$

\subsection{Absorption Properties}

The absorption properties of diaryliodonium salts are well known in the literature, for example, for diphenyliodonium the maximum absorption wavelength is located at $230 \mathrm{~nm}$ [1]. The UV-visible spectra of S5 and S6 present a broad band in the 300-400 nm region (Figure 5). Contrary to the well-known diphenyliodonium, S5 and S6 present shifted absorption spectra to the near UV region with maximum absorption wavelengths located at $\sim 330 \mathrm{~nm}$. Therefore, compared to diphenyliodonium salt, the aryliodonium ylides S5 and S6 lead to a shift of the absorption spectra to longer wavelengths. Remarkably, the newly proposed aryliodonium ylides present rather good absorption properties at $365 \mathrm{~nm}\left(\varepsilon: 532 \mathrm{M}^{-1} . \mathrm{cm}^{-1}\right.$ for S5 and $367 \mathrm{M}^{-1} . \mathrm{cm}^{-1}$ for S6) matching well with the emission spectra of common mercury lamps used in the coatings industry, and could therefore be used as photoinitiators in this application. For industrial fields using blue light irradiation, for example, dentistry, S5 and S6 must be sensitized by camphorquinone to form initiating radicals under visible light irradiation. Accordingly, no radicals were observed in ESR experiments upon blue light without camphorquinone. 


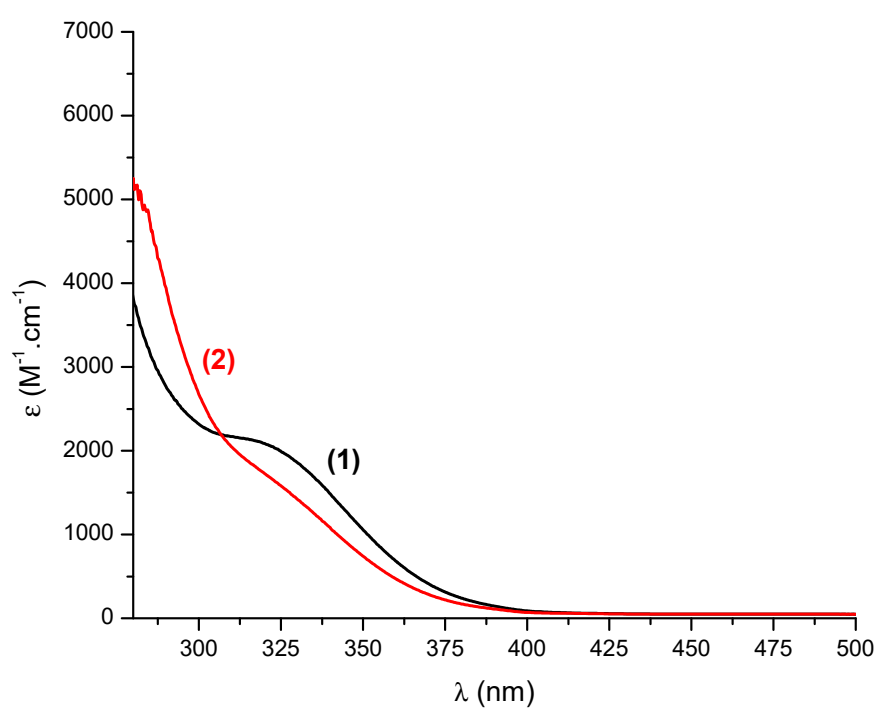

Figure 5. UV-visible spectra of (1) S5 and (2) S6 in acetonitrile.

\section{3. $C Q / E D B / S 5$ and $C Q / E D B / S 6$ Initiating Ability}

The polymerization profiles of thick films $(1.4 \mathrm{~mm})$ of Spectrum ${ }^{\circledR} \mathrm{TPH}^{\circledR} 3$ resin upon exposure to the blue LED at $477 \mathrm{~nm}$ (SmartLite Focus) using different photoinitiating systems are presented in Figure 3. Under air, using a $300 \mathrm{~mW} \cdot \mathrm{cm}^{-2}$ light intensity, the systems CQ/EDB/S5 and CQ/EDB/S6 exhibited very good polymerization ability in thick samples. High polymerization rates Rp and high final methacrylate conversions (FCs) up to $80 \%$ were obtained for the systems CQ/EDB/S5 and $\mathrm{CQ} / \mathrm{EDB} / \mathrm{S6}$ (curves 3-4 Figure 3). Remarkably, similar or better performances were obtained for the two PISs investigated, compared to the reference systems CQ/EDB and CQ/EDB/SC938 (curves 1-2 Figure 3).

Similar results were obtained using an LED centered at $455 \mathrm{~nm}$ for the polymerization of thick $(1.4 \mathrm{~mm})$ samples of Spectrum ${ }^{\circledR} \mathrm{TPH}^{\circledR} 3$ resin under air. The polymerization profiles of thick films $(1.4 \mathrm{~mm})$ of Spectrum ${ }^{\circledR} \mathrm{TPH}^{\circledR} 3$ resin upon exposure to the LED at $455 \mathrm{~nm}$ using different photoinitiating systems are presented in Figure 4. Remarkably, the CQ/EDB/S5 and CQ/EDB/S6 systems lead to higher final conversions and polymerization rates than the reference system CQ/EDB.

Remarkably, good bleaching properties were obtained with the systems CQ/EDB/S5 and $\mathrm{CQ} / \mathrm{EDB} / \mathrm{S6}$ compared to the references CQ/EDB and CQ/EDB/SC938 after 115s of irradiation with the blue LED centered at $477 \mathrm{~nm}$. Similar or better bleaching properties are obtained with the newly developed PISs compared to those achieved with the reference PISs (Figure 6).

\subsection{CQ/EDB/S5 and CQ/EDB/S6 for the Polymerization of Thin Samples of Methacrylates and Adhesives under Air}

The newly proposed PISs CQ/EDB/S5 and CQ/EDB/S6 showed excellent polymerization performances for the polymerization of thick $(1.4 \mathrm{~mm})$ samples of methacrylates under air upon exposure to a blue LED centered at $477 \mathrm{~nm}$ and an LED centered at $455 \mathrm{~nm}$. The performances of these systems were also investigated for the preparation of thin $(20 \mu \mathrm{m})$ samples of methacrylates under exposure to the LED centered at $477 \mathrm{~nm}$ (Figure 7). Remarkably, the system CQ/EDB/S5 presented an enhanced polymerization rate and final methacrylate function conversion ( $35 \%$ vs. $25 \%)$ compared to the reference system CQ/EDB for polymerization under air. The lower conversion in Figure 7 compared to Figures 3 and 4 was ascribed to the oxygen inhibition that is stronger for thin samples compared to thick ones. 


\begin{tabular}{|c|c|c|}
\cline { 2 - 3 } \multicolumn{1}{c|}{} & Before irradiation & Afterirradiation \\
\hline $\begin{array}{c}\text { CQ/EDB } \\
(0.2 / 0.5 \% \mathrm{w} / \mathrm{w})\end{array}$ & \\
\hline $\begin{array}{c}\mathrm{CQ} / \mathrm{EDB} / \mathrm{SC} 938 \\
(0.2 / 0.5 / 1 \% \mathrm{w} / \mathrm{w})\end{array}$ & & \\
\hline $\begin{array}{c}\mathrm{CQ} / \mathrm{EDB} / \mathrm{S5} \\
(0.2 / 0.5 / 1 \% \mathrm{w} / \mathrm{w})\end{array}$ & & \\
\hline & & \\
\hline $\begin{array}{c}\text { CQ/EDB/S6 } \\
(0.2 / 0.5 / 1 \% \mathrm{w} / \mathrm{w})\end{array}$ & & \\
\hline
\end{tabular}

Figure 6. Photos of the samples before and after polymerization (under air; thickness $=1.4 \mathrm{~mm}$; SmartLite Focus (300 $\left.\mathrm{mW} \cdot \mathrm{cm}^{-2}\right)$; $115 \mathrm{~s}$ irradiation): (1) CQ/EDB $(0.2 / 0.5 \% \mathrm{w} / \mathrm{w}) ;$ (2) CQ/EDB/SC938 $(0.2 / 0.5 / 1 \% w / w) ;(3) \mathrm{CQ} / \mathrm{EDB} / \mathrm{S} 5(0.2 / 0.5 / 1 \% w / w) ;(4) \mathrm{CQ} / \mathrm{EDB} / \mathrm{S} 6(0.2 / 0.5 / 1 \% w / w)$ in Spectrum ${ }^{\circledR}$ $\mathrm{TPH}^{\circledR} 3$.

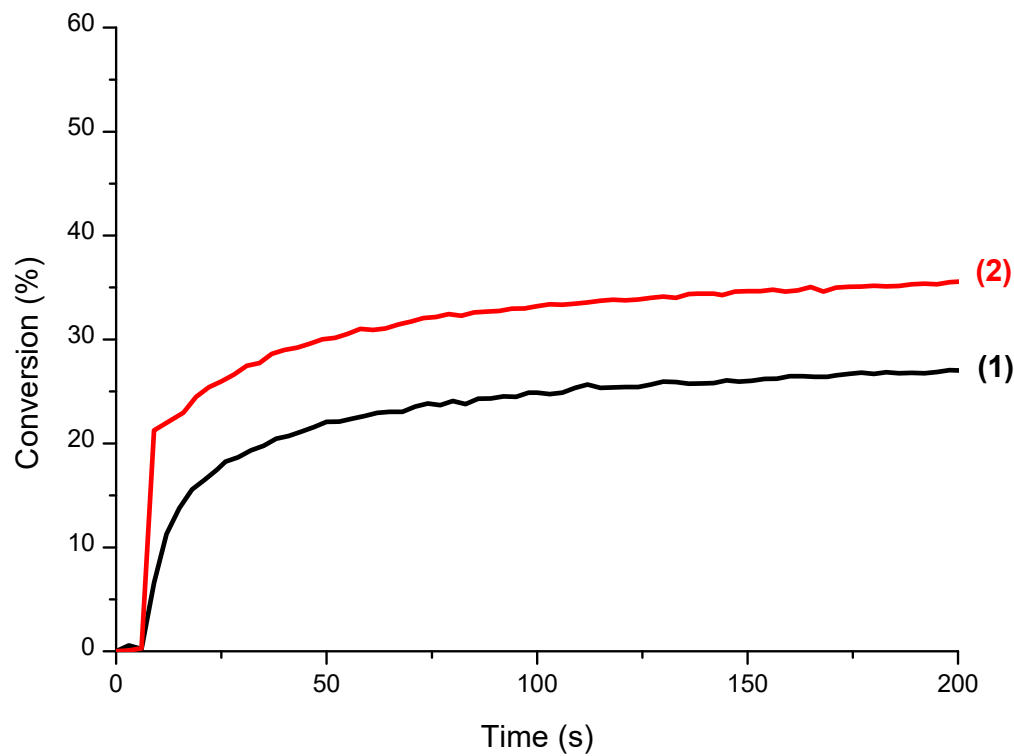

Figure 7. Photopolymerization profiles (methacrylate function conversion vs. irradiation time) for a BisGMA/TEGDMA (70/30 \% $w / w)$ resin blend (under air; $20 \mu \mathrm{m}$ thin films) upon exposure to the LED@477 $\mathrm{nm}\left(\mathrm{I}_{0}=300 \mathrm{~mW} \cdot \mathrm{cm}^{-2}\right)$ using different photoinitiating systems. (1) CQ/EDB $(1 / 1 \% w / w)$; (2) $\mathrm{CQ} / \mathrm{EDB} / \mathrm{S} 5(1 / 1 / 1 \% w / w)$. The irradiation starts for $\mathrm{t}=5 \mathrm{~s}$.

The newly proposed systems were also investigated for the preparation of very thin $(\sim 13 \mu \mathrm{m})$ samples of adhesives by polymerization under air under exposure to the blue dental LED. The polymerization profiles of thin adhesive films $(\sim 13 \mu \mathrm{m})$ of Prime\&Bond Active ${ }^{\circledR}$ formulation upon exposure to the blue LED at $477 \mathrm{~nm}$ (SmartLite Focus) using different photoinitiating systems are 
depicted in Figure 8. Remarkably, better polymerization performances (i.e., higher final methacrylate function conversions and higher polymerization rates) were achieved for the systems CQ/DMABN/S5 and CQ/DMABN/S6 compared to the reference system CQ/DMABN. The new systems proposed presented excellent performances for the polymerization in difficult conditions, for example, for very thin samples and under air.

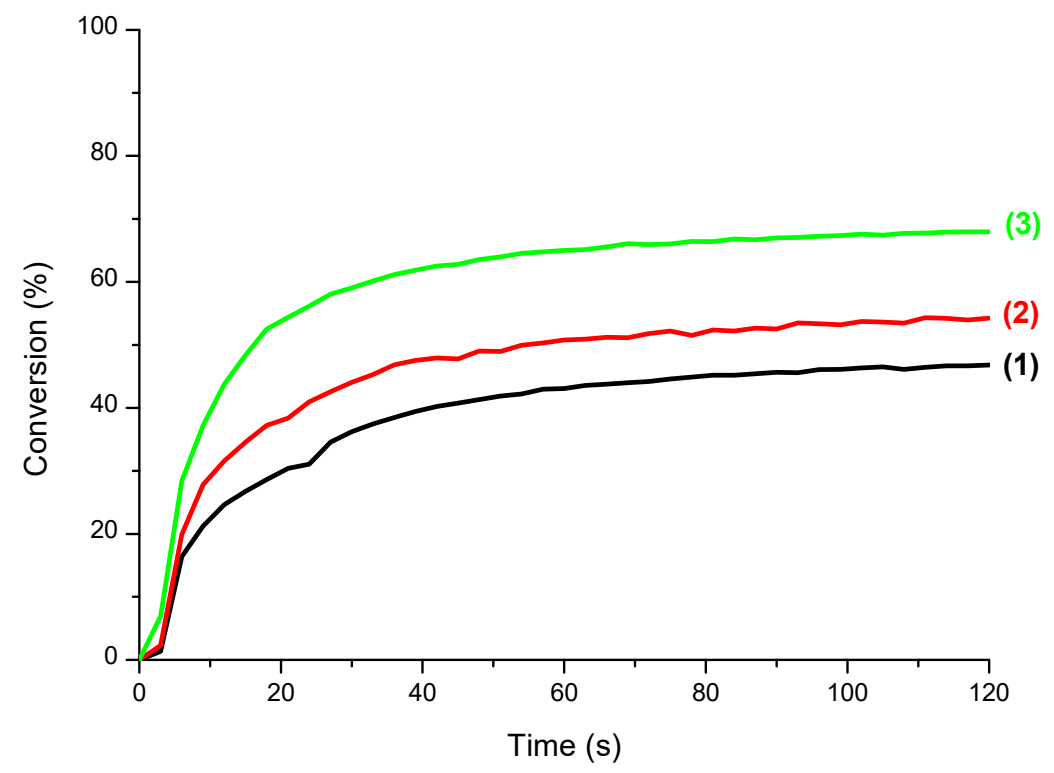

Figure 8. Photopolymerization profiles (methacrylate function conversion vs. irradiation time) for Prime\&Bond Active ${ }^{\circledR}$ resin (under air; $13 \mu \mathrm{m}$ thin films) upon exposure to the LED@477 nm $\left(\mathrm{I}_{0}\right.$ $\left.=300 \mathrm{~mW} \cdot \mathrm{cm}^{-2}\right)$ using different photoinitiating systems. (1) $\mathrm{CQ} / 4$-(dimethylamino)benzonitrile (DMABN) (1.5/0.6 \% w/w); (2) CQ/DMABN/S5 (1.5/0.6/0.75\% w/w); (3) CQ/DMABN/S6 (1.5/0.6/0.75\% $w / w)$. The irradiation starts for $\mathrm{t}=5 \mathrm{~s}$.

\section{Conclusions}

In the present paper, aryliodonium ylides (AY) were reported as new high performance iodonium salts and efficient additives for $\mathrm{CQ} /$ amine based systems for the polymerization of methacrylates under blue light irradiation. Enhanced polymerization performances were achieved for the system $\mathrm{CQ} /$ amine/AY compared to the reference system CQ/amine. Good bleaching properties of the final polymers were also obtained after polymerization. Interestingly, the newly developed CQ/amine/AY systems presented excellent initiating ability in strongly oxygen-inhibited conditions (thin samples, under air), for example, for the preparation of adhesives. Aryliodonium ylides therefore represent a new class of iodonium salts for photoinitiated polymerization and an interesting alternative to the well-known diaryliodonium salts. Remarkably, as the counter anion is located on the iodonium moiety, enhanced solubility in monomers is expected, as well as reduced formation of side products, compared to the classical diaryliodonium salts, especially diaryliodonium hexafluorophosphate.

Author Contributions: Conceptualization and methodology, J.E.K., J.L.; Investigation, J.K., J.P., M.B.-Z.; Data curation, J.K., J.P., M.B.-Z.; Writing—original draft preparation, J.K., M.B.-Z.; Writing—review and editing, J.-M.B., J.E.K., S.C., S.L. and J.L.

Funding: This research was funded by Dentsply Sirona.

Acknowledgments: IS2M authors thank Dentsply Sirona and the Grand Est region for the funding of this work. The authors also thank Valérie Monnier (Spectropole, Aix Marseille University) for the MS experiments.

Conflicts of Interest: The authors declare no conflict of interest. 


\section{References}

1. Fouassier, J.P.; Lalevée, J. Photoinitiators for Polymer Synthesis-Scope, Reactivity and Efficiency; Wiley-VCH Verlag GmbH \& Co. KGaA: Weinheim, Germany, 2012.

2. Yagci, Y.; Jockusch, S.; Turro, N.J. Photoinitiated polymerization: Advances, challenges and opportunities. Macromolecules 2010, 43, 6245-6260. [CrossRef]

3. Nakabayashi, N. Contribution of polymer chemistry to dentistry: Development of an impermeable interpenetrating polymer network to protect teeth from acid demineralization. Polym. Int. 2008, 57, 159-162. [CrossRef]

4. Irving, H.; Reid, R.W. 421. The photochemical decomposition of diphenyliodonium iodide. J. Chem. Soc. 1960, 2078-2081. [CrossRef]

5. Nickol, S.L.; Kampmeier, J.A. Photolysis of a charge transfer complex. Triphenylsulfonium iodide. J. Am. Chem. Soc. 1973, 95, 1908-1915. [CrossRef]

6. Ortyl, J.; Popielarz, R. New photoinitiators for cationic polymerization. Polimery 2012, 57, 510-517. [CrossRef]

7. Crivello, J.V. The discovery and development of onium salt cationic photoinitiators. J. Polym. Sci. Part A Polym. Chem. 1999, 37, 4241-4254. [CrossRef]

8. Crivello, J.V. Cationic polymerization-Iodonium and sulfonium salt photoinitiators. In InitiatorsPoly-Reactions_Optical Activity; Advances in Polymer Science; Springer: Berlin/Heidelberg, Germany, 1984; Volume 62.

9. Crivello, J.V.; Lam, J.H.W. Diaryliodonium salts. A new class of photoinitiators for cationic polymerization. Macromolecules 1977, 10, 1307-1315. [CrossRef]

10. Mokbel, H.; Toufaily, J.; Hamieh, T.; Dumur, F.; Campolo, D.; Gigmes, D.; Fouassier, J.P.; Ortyl, J.; Lalevée, J. Specific cationic photoinitiators for near UV and visible LEDs: Iodonium versus ferrocenium structures. J. Appl. Polym. Sci. 2015, 132, 42759. [CrossRef]

11. Hua, Y.; Crivello, J.V. Development of polymeric photosensitizers for photoinitiated cationic polymerization. Macromolecules 2001, 34, 2488-2494. [CrossRef]

12. Walsh, T.D.; Long, R.C. Photochemistry of aromatic ions. Photolysis of quaternary anilinium salts. J. Am. Chem. Soc. 1967, 89, 3943-3944. [CrossRef]

13. Kabatc, J.; Ortyl, J.; Kostrzewska, K. New kinetic and mechanistic aspects of photosensitization of iodonium salts in photopolymerization of acrylates. RSC Adv. 2017, 7, 41619-41629. [CrossRef]

14. Devoe, R.J.; Sayhun, M.R.V.; Serpone, N.; Sharma, D.K. Transient intermediates in the photolysis of iodonium cations. Can. J. Chem. 1987, 65, 2342-2349. [CrossRef]

15. Dektar, J.L.; Hacker, N.P. Photochemistry of diaryliodonium salts. J. Org. Chem. 1990, 55, 639-647. [CrossRef]

16. Jakubiak, J.; Allonas, X.; Fouassier, J.P.; Sionkowska, A.; Andrzejewska, E.; Linden, L.A.; Rabek, J.F. Camphorquinone-amines photoinitiating systems for the initiation of free radical polymerization. Polymer 2003, 44, 5219-5226. [CrossRef]

17. Bi, Y.; Neckers, D.C. A visible light initiating system for free radical promoted cationic polymerization. Macromolecules 1994, 27, 3683-3693. [CrossRef]

18. Cook, W.D. Photopolymerization kinetics of dimethacrylates using the camphorquinone/amine initiator system. Polymer 1992, 33, 600-609. [CrossRef]

19. Shiraishi, A.; Kimura, H.; Oprych, D.; Schmitz, C.; Strehmel, B. Comparison between NIR and UV-sensitized radical and cationic reactivity of iodonium salts comprising anions with different coordination behavior. J. Photopolym. Sci. Technol. 2017, 30, 633-638. [CrossRef]

20. Shiraishi, A.; Ueda, Y.; Schläpfer, M.; Schmitz, C.; Brömme, T.; Oprych, D.; Strehmel, B. NIR-sensitized photopolymerization with iodonium salts bearing weak coordination anions. J. Photopolym. Sci. Technol. 2016, 29, 609-615. [CrossRef]

21. Huddleston, J.G.; Visser, A.E.; Reichert, W.M.; Willauer, H.D.; Broker, G.A.; Rogers, R.D. Characterization and comparison of hydrophilic and hydrophobic room temperature ionic liquids incorporating the imidazolium cation. Green Chem. 2001, 3, 156-164. [CrossRef]

22. Tseng, M.C.; Liang, Y.M.; Chu, Y.H. Synthesis of fused tetrahydro- $\beta$-carbolinequinoxalinones in 1-n-butyl-2,3-dimethylimidazolium bis(trifluoromethylsulfonyl)imide ([bdmim][Tf $\left.\left.{ }_{2} \mathrm{~N}\right]\right)$ and 1-n-butyl-2,3-dimethylimidazolium perfluorobutylsulfonate ([bdmim] $\left.\left[\mathrm{PFBuSO}_{3}\right]\right)$ ionic liquids. Tetrahedron Lett. 2005, 46, 6131-6136. [CrossRef] 
23. Schank, K.; Lick, C. Ozonolytic fragmentation of phenyliodonium $\beta$-diketonates; a convenient synthesis of unsolvated vic-triketones. Synthesis 1983, 5, 392-395. [CrossRef]

24. Tehfe, M.A.; Lalevée, J.; Telitel, S.; Sun, J.; Zhao, J.; Graff, B.; Morlet-Savary, F.; Fouassier, J.P. Iridium complexes incorporating coumarin moiety as catalyst photoinitiators: Towards household green LED bulb and halogen lamp irradiation. Polymer 2012, 53, 2803-2808. [CrossRef]

25. Criqui, A.; Lalevée, L.; Allonas, X.; Fouassier, J.P. Electron spin resonance spin trapping technique: Application to the cleavage process of photoinitiators. Macromol. Chem. Phys. 2008, 209, 2223-2231. [CrossRef]

Sample Availability: Samples of the compounds S5 and S6 are available from the authors.

(C) 2019 by the authors. Licensee MDPI, Basel, Switzerland. This article is an open access article distributed under the terms and conditions of the Creative Commons Attribution (CC BY) license (http://creativecommons.org/licenses/by/4.0/). 